\title{
ESTRUTURA DE EVENTOS E AQUISIÇÃO DE TEMPO E ASPECTO NO PORTUGUÊS BRASILEIRO (PB)
}

\author{
DENISE MIOTTO MAZOCCO ${ }^{1}$ \\ (UFPR) \\ TERESA CRISTINA WACHOWICZ² \\ (UFPR)
}

\begin{abstract}
RESUMO: Este artigo tem como foco a aquisição das categorias tradicionalmente nomeadas como aspecto lexical e aspecto gramatical, em sua relação com o tempo, em crianças nativas do português brasileiro (PB). A questão central que nos motiva é se há uma hierarquia dessas categorias durante o processo de aquisição, na discussão também sedimentada na Hipótese da Primazia do Aspecto Lexical e na Hipótese da Primazia do Aspecto Gramatical (DELIDAKI, 2006). Como pergunta consequente, as mesmas categorias mostraram-se conceitualmente frágeis diante da variedade de dados que nos emergiu. Logo, como primeira hipótese, podemos defender que o aspecto lexical desdobra-se à estrutura de evento, defendida desde Moens \& Steedman (1988), e explicitada na derivação sintática desde Swart (1998), sob operações de aspecto gramatical e tempo. No entanto, as categorias parecem obedecer a uma hierarquia derivacional que toma léxico e gramática em duas 'zonas' de interpretação (SVENONIOUS \& RAMCHAND, 2013). Conceitualmente, a noção de (a)telicidade em oposição à (im)perfectividade torna-se questionável, dado que a estrutura de evento codifica mais informações do que o telos da situação, como informação de causa, resultado, trajetória, lugar. Em dados longitudinais e de experimentos, coletados sob projeto de pesquisa na UFPR (Construção de banco de dados para estudos de aquisição de tempo e aspecto no PB, 2008-2012), observamos que as crianças do PB leem antes a configuração do evento e depois operam o tempo. Relativamente à convergência 'télico/perfectivo', verificamos assimetria entre dados de compreensão e produção.
\end{abstract}

Palavras-chave: aspecto; tempo; aquisição

${ }^{1}$ Doutorado, bolsista CAPES, Universidade Federal do Paraná (UFPR). denisemazocco@hotmail.com

${ }^{2}$ Professora Associada, Universidade Federal do Paraná (UFPR). tecacw@gmail.com 
ABSTRACT: This paper focuses on the acquisition of the categories traditionally named as lexical aspect and grammatical aspect, in their relation with tense, in children acquiring Brazilian Portuguese (BP). The main question that motivated us is if there is a hierarchy of these categories in the acquisition process, as discussed in the Aspect First Hypothesis and the Grammatical Aspect First Hypothesis. As a consequential question, the same categories were conceptually fragile in view of the variety of the collected data. Therefore, our first hypothesis is that the lexical aspect is placed in an event structure defended since Moens \& Steedman (1988) and presented in syntactic derivations since Swart (1998), under grammatical aspect and tense operations. However, the categories seem to obey a derivational hierarchy that takes the lexicon and the grammar in two interpretation phases (SVENONIOUS \& RAMCHAND, 2013). Conceptually, the notion of telicity as opposed to (im)perfectiveness becomes questionable, since the event structure encodes more information than just the telos of the event, such as cause, result, path, place. Through the analysis of longitudinal (production) and experimental (comprehension) data, collected on a research project at UFPR (Data base construction for temporal and aspectual acquisition studies, 2008-2012), we observed that children acquiring BP first read the event configuration, and afterwards operate on tense. As for the telic/perfective convergence, we observed an asymmetry in the comprehension and production data.

Keywords: aspect; time, acquisition

\section{INTRODUÇÃO}

Este trabalho surge de um incômodo referente às hipóteses, com mais frequência testadas, sobre aquisição de tempo e aspecto, as quais propõem ou a primazia do aspecto lexical ou a do gramatical sobre o tempo (DELIDAKI, 2006). No primeiro caso, temos a telicidade como desencadeadora da aquisição das demais categorias; já no segundo, a distinção entre perfectivo e imperfectivo. Ambas, porém, não se aprofundam na discussão sobre a definição dessas categorias e levam em conta a distribuição fixa da telicidade entre as quatro classes acionais vendlerianas (estado, atividade, accomplishment, achievement).

Vemos um problema nisso ao nos depararmos com outra proposta teórica, de representação de eventos, que considera projeções de subeventos na estrutura de sintaxe de primeira fase, ou Nanosssintaxe (RAMCHAND \& SVENONIOUS, 2014; RAMCHAND, 2008). O problema se estende ao observarmos resultados de produção longitudinais, de experimentos de compreensão que fogem ao previsto pelas hipóteses em questão. Logo, nossas questões norteadoras envolvem dados ao mesmo tempo heterogêneos e instigantes das crianças, paralelamente à investigação teórica de como explicá-los.

Partindo dessa discussão, propomos que a criança, na aquisição do PB, reconhece estrutura de evento, em seus desdobramentos aspectuais, temáticos e causais, ao passo que o adulto já opera a interpretação sob o escopo temporal. Em dados de produção, as convergências temporais e aspectuais das hipóteses tradicionais podem ganhar novos questionamentos, o que nos aproxima da hipótese de um sincretismo inicial entre as categorias, sugerido inicialmente em Bertinetto (2009).

A seção 2 deste artigo tem o objetivo de levantar o quadro das hipóteses de aquisição de aspecto (lexical e gramatical) e tempo, centrando-se em Delidaki (2006). Na seção 3, introduzimos as vertentes teóricas do aspecto lexical, inserindo a proposta da Nanossintaxe como a alternativa de estruturação de eventos em derivação sintática. Na seção 4, expomos dois experimentos de compreensão e dados de produção longitudinais, que endossam as hipóteses centrais do trabalho. 


\section{HIPÓTESES SOBRE AQUISIÇÃO DE TEMPO E ASPECTO}

Grande parte dos trabalhos referentes à aquisição de tempo e aspecto, em diferentes línguas, giram em torno de hipóteses de condicionamento de uma categoria sobre a outra. Delidaki (2006) discute esses trabalhos e os divide em dois grupos: os que defendem a chamada Lexical Aspect First Hypothesis (LAFH) e os que defendem a Grammatical Aspect First Hypothesis (GAFH). A primeira consiste em defender a primazia do aspecto lexical em relação ao tempo e ao aspecto gramatical na aquisição, enquanto a segunda propõe que a escolha do tempo pela criança não é influenciada pelo aspecto lexical, mas sim pela informação de completude, pelo aspecto gramatical. Bertinetto (2009), por sua vez, apresenta outra hipótese: as categorias de tempo, modo, aspecto e acionalidade seriam adquiridas de forma sincrética e depois especificadas pela criança ao longo da fase de aquisição. Discutiremos, nesta seção, um pouco de cada hipótese, a fim de mostrar alguns problemas com relação à definição das categorias e às explicações fornecidas.

\subsection{Hipótese da Primazia do Aspecto Lexical}

Segundo Delidaki (2006), para a LAFH, o tempo e aspecto gramatical seriam usados de forma equivocada pela criança para marcar aspecto lexical, seguindo o padrão: tempo passado e perfectivo combinados com predicados télicos; e tempo presente e imperfectivo combinados com predicados atélicos. Nos desdobramentos dessa hipótese, a autora observa duas versões. Há a versão forte, segundo a qual as crianças não entenderiam e consequentemente não expressariam informação temporal. Na produção, somente verbos télicos seriam flexionados no passado, enquanto que atividades e estados nunca seriam usados para se referir a situações em momentos anteriores ao de fala. O trabalho de Antinucci e Miller (1976, apud Delidaki, 2006) foi um dos que defendeu essa hipótese, após analisarem dados de produção espontânea de crianças (sete italianas e uma americana) com idade entre 1;6 e 2;5. Desses dados, eles observaram que o passado composto perfectivo (passato prossimo), combinado com eventos télicos que apresentam um resultado claro, é o primeiro a aparecer, e que o passado não tem valor temporal, e sim aspectual. Já os eventos atélicos, marcados com presente e passado imperfectivo, aparecem em torno de 2;1. Partindo disso, os autores explicam que as crianças não adquiriram ainda habilidades cognitivas relevantes para compreender tempo. Delidaki (2006) contesta essa afirmação ao mostrar, posteriormente, em um teste com crianças gregas, que elas compreendem informações temporais.

Por outro lado, há uma versão fraca da LAFH, que defende a influência do aspecto lexical sobre o tempo e aspecto gramatical, mas não de uma forma absoluta. Bronckart e Sinclair (1973), por exemplo, realizaram um experimento com crianças falantes nativas do francês. No teste, eventos foram encenados em frente às crianças, as quais, por sua vez, deveriam descrevê-los. Esses eventos dividiam-se em três grupos: (i) eventos perfectivos, que apresentam resultado e cobrem certa distância no espaço, terminando em determinado local; (ii) eventos imperfectivos, que são ações sem resultados; e (iii) eventos aperfectivos, os que são percebidos por audição, como barulhos produzidos por animais, ou o choro 
de um bebê. Como resultado, os autores observaram que a escolha do tempo pela criança segue a relação (BRONCKART E SINCLAIR, 1973, p. 11): para ações com resultado, o uso do passado composto (passé composé), para ações sem um objetivo intrínseco, o presente ou o passado composto (présent ou passé composé), e para as ações com nenhum resultado, o presente (présent).

Delidaki (2006) testa a LAFH - tomando como base o experimento de Bronckart e Sincair (1973) - com crianças gregas e observa uma diferença significativa entre produção e compreensão. No teste de produção com crianças de $3 ; 0$ a 6;3 anos, a autora observou que, na descrição dos eventos que foram encenados (com o uso de brinquedos) em frente às crianças, a maioria delas escolhia o aspecto gramatical e o tempo verbal em função da telicidade do evento, seguindo a LAFH. Contudo, Delidaki (2006) apontou uma questão curiosa resultante do teste, porém, por ela, pouco explorada, que foi o fato de os adultos se aproximarem mais do que as crianças do padrão considerado na LAFH. A autora, diante disso, sugere que a combinação prevista talvez faça parte da gramática do grego. Isso até poderia sinalizar a conjectura de um caminho inverso: a relação estreita entre as três categorias seria um ponto final da aquisição.

Por outro lado, o teste de compreensão realizado por Delidaki (2006) sugere uma divergência da hipótese em questão. Aqui, além de investigar se a compreensão do tempo verbal e do aspecto gramatical pela criança é influenciada pelo aspecto lexical, a autora coloca em discussão também o fato de a criança ter ou não habilidade cognitiva para compreender tempo antes de adquirir a morfologia. Trabalhos como Bronckart e Sinclair (1973) e Antinucci e Miller (1976, apud DELIDAKI 2006) defendem que não, enquanto Wagner (2001) defende que sim. O teste de Delidaki, realizado com crianças de 2;8 a 4;1 anos, vai mostrar que elas compreendem tempo, antes de adquirir a morfologia. A autora selecionou 3 eventos télicos e 3 atélicos, os quais foram encenados, com o uso de brinquedos, em frente à ilustração de uma estrada, desenhada num papel, com três lugares correspondentes aos lugares do passado, presente e futuro, respectivamente. A pesquisadora encenava o evento no primeiro lugar até o final, depois começava a encenar o mesmo evento no segundo lugar. Nisso, fazia as perguntas (por exemplo: Onde o coelho construiu a casa?), variando o tempo verbal e o aspecto gramatical. Em resposta, o sujeito deveria apontar o local correspondente. Como resultado, a autora observou que o aspecto lexical parece não influenciar a escolha entre os tempos passado e presente pela criança ou entre perfectivo e imperfectivo (no passado). Logo, o teste de compreensão não corrobora a LAFH no grego. Porém, o futuro parece ser influenciado pelo aspecto lexical, pelo menos no caso das crianças menores de 3;3. Nos predicados atélicos, o resultado foi mais próximo do esperado (crianças indicarem o terceiro lugar, em que o evento ainda não havia sido realizado). Mas nos predicados télicos, houve uma distribuição maior entre os que indicaram o segundo lugar (onde o evento estava ocorrendo) e o terceiro. Vale observarmos que nem a Hipótese da Primazia do Aspecto Lexical nem a do Aspecto Gramatical preveem um padrão para a aquisição do futuro. Nesse sentido, precisamos de uma discussão maior sobre essa categoria, incluindo uma problematização sobre a sua caracterização 
dentro do domínio do tempo. Em nossos dados longitudinais, ${ }^{3}$ por exemplo, há ocorrências do futuro perifrástico nas crianças a partir dos 2 anos, como em: AL(2,1 - 2,3).eu vô deitá... bebê... Eu vô quebrá bebezinhu. Esse dado pode sinalizar uma referência ao contexto imediato da criança, mais uma evidência para a necessidade de se repensar a definição dessa categoria.

Em todo caso, Delidaki (2006) constata, assim, uma assimetria entre produção e compreensão. Essa assimetria nos permite questionar se dados de produção seriam suficientes para mostrar um condicionamento entre as categorias. Para defender uma hierarquia na aquisição, teria que se chegar a um argumento linguístico, algo que não se observa nos trabalhos vistos até então.

Em nosso experimento de compreensão, nas seções 4.1 e 4.2, observaremos que as crianças pequenas são pouco sensíveis à leitura temporal nos eventos tradicionalmente télicos; na seção 4.3, evidenciaremos uma correlação do presente/imperfectivo com sentenças de apresentação ("tem coelhinho aqui"), e do passado perfectivo com sentenças de passado recente ou dêitico (LOPES, 2003): mais alguns ingredientes que convergem a uma postura de cautela em relação a teorias de antecedência entre as categorias de tempo e aspecto.

\subsection{Hipótese da Primazia do Aspecto Gramatical}

Outra hipótese, que advém dos trabalhos cujos experimentos não apontaram nenhuma relação entre o aspecto lexical e as demais categorias em questão, é a da Primazia do Aspecto Gramatical. A conclusão de Delidaki (2006) de que a criança compreenderia tempo se contrapõe à GAFH. Já Wagner (2001) defende essa hipótese. Em seu experimento, as crianças (de 2 a 3 anos) assistiram a um vídeo com um evento realizado em dois distintos lugares ao longo de uma estrada. Enquanto era realizado no segundo lugar, foram feitas questões na forma presente + imperfectivo e no passado + imperfectivo, tais como: Onde o gato estava montando/está montando o quebra-cabeça? Como resultado, a autora observa que as crianças de 2 a 3 anos não usam a informação temporal dêitica para resolver a questão, mas usam a ideia da completação do evento.

Delidaki (2006), por sua vez, contesta essa hipótese ao realizar também testes de produção e compreensão. No primeiro, com crianças de 3;6 a 6;5 anos, em que elas também tinham que descrever eventos encenados, a autora constatou diferentes formas utilizadas para distinguir eventos completos de incompletos, entre as quais a mais comum é o uso de um advérbio de grau (metade, todo). Além disso, ela observou que o uso do tempo verbal não é influenciado pela completude ou não do evento, visto que a grande maioria dos sujeitos usou o passado perfectivo independente da completude. Isso está de acordo com o encontrado no experimento de produção para testar a LAFH, onde as crianças e adultos usaram a morfologia do perfectivo para todos os verbos télicos, completados ou não.

${ }^{3}$ Os dados fazem parte do projeto de pesquisa Construção de banco de dados para estudos de aquisição de tempo e aspecto no PB (2008-2012), UFPR. 
Já no teste de compreensão (referente à GAFH), realizado por Delidaki (2006), com crianças de 2;8 a 4;5 anos, foram encenados eventos télicos, 3 de modo completo e 3 de modo incompleto com uma interrupção, também em uma estrada desenhada num pedaço de papel, na qual foram distinguidos dois locais: inicial, correspondente ao passado imperfectivo, e outro correspondente ao evento em andamento, presente. Um coelho encenava o evento no primeiro local, depois ia para o segundo, momento em que o pesquisador fazia as perguntas no passado imperfectivo e no presente. Em resposta, as crianças deveriam apontar os lugares. Como resultado observado, parece que a completude não influencia na escolha do tempo verbal. Segundo a autora, a GAFH não funciona para as crianças gregas, elas entendem passado e presente com base na sequenciação da informação temporal, e não com base na completação do evento. Seria um indício de que a aquisição do tempo não é resultante diretamente da aquisição do aspecto gramatical?

Os testes de Delidaki (2006) não confirmam absolutamente nenhuma das duas hipóteses. Apenas seu primeiro teste de produção (apresentado em 2.1) aponta uma direção que se aproxima da LAFH. Além disso, a autora critica os trabalhos que defendem a primazia do aspecto lexical ou do gramatical, pelo fato de não apresentarem uma explicação convincente para o possível condicionamento. Ela revela também uma dificuldade em comparar os resultados obtidos por esses diferentes trabalhos, dadas as discrepâncias entre procedimentos metodológicos e definições das categorias utilizadas.

A crítica de Delidaki (2006) se aproxima da de Bertinetto (2009). O autor, além de destacar que nessas hipóteses o tempo se torna secundário, considera que as correlações propostas são muito simplistas, uma vez que em sua maioria sugerem que o aspecto lexical e/ou o aspecto gramatical são usados como desencadeadores da aquisição da categoria de tempo, mas não explicam como e/ou por que ocorre essa correlação. Segundo Bertinetto (2009, p. 4), para defendê-las, é preciso assumir que uma categoria, do aspecto lexical ou gramatical, é dominada pela criança em fase de aquisição de uma forma muito madura desde o início.

\subsection{A hipótese do ATAM}

Bertinetto (2009) então propõe que não há uma categoria desencadeadora, o que acontece é que criança adquire uma categoria sincrética em que aspecto, tempo, acionalidade e modo estão interligados, domínio denominado ATAM (acrônimo com as iniciais de cada categoria), depois ela iria especificando e adquirindo restrições conforme o input recebido de sua língua materna. Nesse processo, a criança desenvolveria noções cognitivas - tais como os pares opostos estado e processo, eventos completos e incompletos, agora e não agora, real e não real (BERTINETTO, 2009, p. 7) -, que dariam sustentação à gradual distinção dessas categorias. Essas noções não espelham as categorias de tempo, aspecto, modo e acionalidade, mas estão relacionadas com elas. $\mathrm{O}$ autor destaca exemplos do sincretisto: 'statelincomplete-event $\backslash n$ ow $\backslash$ realis' vs. 'process $\backslash$ complete-event not-nowlirrealis'. (BERTINETTO, 2009, p. 7). 
Com essa proposta do sincretismo, Bertinetto (2009) se contrapõe aos trabalhos que defendem uma estratégia fixa para a aquisição de tempo, aspecto e acionalidade, o que ele chamou de universalismo ingênuo. Para o autor, a única característica comum, nesse caso, aos seres humanos seria o desenvolvimento cognitivo que os permite extrair as informações relevantes do input de sua língua materna. Ainda assim, o autor não afirma categoricamente que esse desenvolvimento seria anterior ao gramatical.

Em Bertinetto et. all (2007-8), por exemplo, foram analisados dados longitudinais de três crianças italianas, a fim de observar um caminho para o processo de especificação das categorias em questão, durante a aquisição. A principal conclusão dos autores é que não é possível dizer que a maturação cognitiva precede a gramatical, uma vez que, se assim o fosse, advérbios e o uso do presente não-referencial apareceriam antes dos tempos verbais passado e futuro, o que não ocorre nos dados. Nas três crianças, o passado perfectivo emerge junto com as primeiras ocorrências do presente não habitual, e ambos antecedem os advérbios referentes ao futuro. (BERTINETTO et. all, 2007-8, p. 9). Além disso, a emergência de advérbios é bem próxima de quando as crianças começam a distinguir a referência passado e presente, por meio de uma morfologia temporal explícita. Já do futuro não houve ocorrências, exceto por apenas uma nos dados de uma das crianças. Ao contrário dos dados do português, em que aparece o futuro perifrástico.

$\mathrm{O}$ confronto entre as hipóteses e os dados aqui mencionados nos coloca num quadro em que é complicado fazer generalizações. A análise de dados longitudinais, de experimentos de produção e de experimentos de compreensão chegam a resultados diferentes. A nossa saída aqui se apresentará na discussão sobre estrutura de eventos, na qual levamos em conta uma relação entre subeventos que ultrapassa a telicidade, e a partir da qual sinalizamos um caminho para a aquisição do PB.

\section{DO ASPECTO LEXICAL À ESTRUTURA DE EVENTO}

Para seguirmos com nossas análises, vamos expor o quadro teórico, especialmente do aspecto lexical, que em nossa hipótese amplifica-se à noção de estrutura de evento, dado que a limitação da configuração temporal das classes accionais mostra-se redutora frente à conceptualização de eventos em que as línguas naturais atuam. No objetivo de localizar sintaticamente a estrutura de evento e operações aspectuais e temporais, recorreremos à sintaxe de primeira fase, ou Nanossintaxe (RAMCHAND, 2008), para delimitar 'zonas' diferentes de estruturação sintático-semântica.

O aspecto lexical, ou o que Vendler (1967) chamou de "esquemas temporais" e, posteriormente, Dowty (1979) nomeou na linguística como "classes accionais", são denotações dos verbos, ilustrados em sentenças, que configuram o "modo particular com que os verbos pressupõem e envolvem 
a noção de tempo". ${ }^{4}$ A terminologia escolhida pelo filósofo e posteriormente pelo linguista Dowty revelam a mão dupla que se instaurou em qualquer trabalho de análise aspectual de verbos: de um lado, a motivação de Vendler é filosófica, o que o legitima a discorrer sobre ontologia de esquemas temporais - estados, atividades, accomplishments e achievements; de outro lado, a motivação de Dowty é linguística, o que igualmente o licencia a representar os verbos por mecanismos decomposicionais, com operadores DO, CAUSE, ACT e BECOME, já nos movimentos iniciais da semântica gerativa. ${ }^{5}$ Verbos como correr (atividade), desenhar (accomplishment) e chutar (achievement) teriam, respectivamente, as seguintes representações, em que $\phi$ e $\psi$ são predicados estativos: [ $\phi$ DO [CAUSE $\psi]$ ]; [ $\phi$ CAUSE [BECOME $\psi]$ ]; e [BECOME $\phi]$.

Uma segunda maneira de representar as classes ontológicas dos verbos busca a tradição componencial de traços. Assim, Smith (1997), Bertinetto (2001), dentre outros, decodificam a análise distintiva de Vendler em três traços: \pm durativo, \pm homogêneo e \pm dinâmico, para aproximar as noções de continuidade, atelicidade e agentividade, respectivamente:

\begin{tabular}{|l|c|c|c|l|}
\hline & {$[ \pm$ durativo] } & {$[ \pm$ homogêneo] } & {$[ \pm$ dinâmico $]$} & \multicolumn{1}{|c|}{ Exemplos } \\
\hline Estados & + & + & - & $\begin{array}{l}\text { amar, saber, ser, estar, } \\
\text { ter, possuir }\end{array}$ \\
\hline Atividades & + & + & + & $\begin{array}{l}\text { correr, nadar, empurrar } \\
\text { o carrinho }\end{array}$ \\
\hline Achievements & - & - & - & $\begin{array}{l}\text { chegar, ganhar ojogo, } \\
\text { perder a caneta }\end{array}$ \\
\hline Accomplishments & + & - & + & $\begin{array}{l}\text { construir a casa, } \\
\text { desenhar um circulo, } \\
\text { pintar o quadro }\end{array}$ \\
\hline
\end{tabular}

Tabela 1: Análise componencial das classes accionais em traços distintivos.

Alguns autores mantêm a tradição, novamente filosófica, do traço \pm télico, uma simetria do \pm homogêneo. Rothstein (2004), por exemplo, rediscute a combinatória de três traços, que resultaria em 9 classes, e propõe a redução a dois ( \pm stage e \pm télico). A noção de estágio, retirada de Landman (1992, apud ROTHSTEIN, 2004) define-se no esboço de uma relação entre subeventos: " $e$ é um estágio de $e^{\prime}$ se $e$ se desenvolve em $e^{\prime \prime \prime}$ (p. 12).

\footnotetext{
4 'the particular way in which that verb pressuposes and involves the notion of time' (VENDLER, 1967, p. 21). (Tradução nossa)

${ }^{5} \mathrm{O}$ movimento da Linguística diante da Filosofia da Linguagem parece se repetir em outros diálogos teóricos. Assim foi em Smith (1978), resgatando o sistema temporal de Reichenbach (1947), um trabalho inicial da lógica temporal, bem como em Parsons (1990), formalizando fenômenos linguísticos, incluindo papel temático e aspecto gramatical, a partir da teoria das ações (ou eventos), da filosofia de Davidson (1967).
} 
Mas uma terceira maneira de conceber e representar as diferentes 'configurações temporais' insere-se pela tradição da semântica de eventos. A partir de Davidson (1967) e Bach (1986), Moens \& Steedman (1988) contrapõem-se à leitura das situações sob o critério essencialmente temporal e assumem que a saída para localizar as classes vendlerianas é o 'evento'. Há insuficiência da noção de intervalo de tempo para as interpretações possíveis das línguas naturais:

Uma semântica de princípios é possível na assunção de que as categorias de tempo, aspecto, advérbios aspectuais, e mesmo proposições, referem uma representação mental de eventos estruturada em princípios não puramente temporais, e para a qual a noção de núcleo, ou seqüência relacionada contingentemente de processo preparatório, evento objetivo e estado conseqüente, é central"' (p. 27). ${ }^{6}$

Um exemplo é relevante: Se alguém disser "Quando eles construíram a ponte,....", a sentença pode ser completada a depender do subevento relevante: 1) o estado inicial, em "...um arquiteto local desenhou a planta"; ou 2) o processo, em "...eles usaram os melhores materiais"; ou o estado resultante, em "...eles resolveram boa parte dos problemas de trânsito". Pictoricamente, um evento padrão do tipo accomplishment teria a seguinte estrutura:

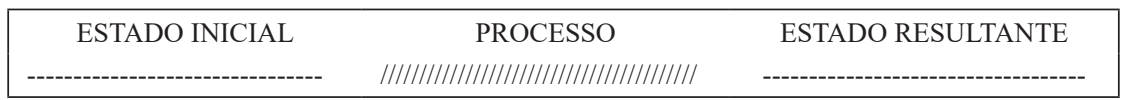

Figura 1: Esboço topológico da estrutura de evento accomplishment.

Pustejovsky (1991) apoia-se na perspectiva topográfica e granulada de subeventos de Moens \& Steedman (1988) para inserir a noção de evento dentro de uma semântica lexical. Mas essa noção, diferentemente de teorias de primitivos que defendem que o significado de uma palavra pode ser exaustivamente definido em termos de um conjunto fixo de primitivos (traços, operações, etc.), e também diferentemente de teorias que defendem entradas polissêmicas, precisa ser uma noção relacional, estruturada, topológica.

Há dois pontos interessantes do pressuposto da estrutura de evento: 1) ela ganha o fundamento 'mental'; logo, parece primitiva, ou próxima ao que Langacker defende como padrão de conceptualização dos eventos do mundo (LANGACKER, 1993; NEGRÃO \& VIOTTI, 2011). Nossa pergunta diante dessa saída para conceber os eventos nos dados das crianças é: Qual é o lugar da estrutura de evento nos dados infantis? 2) O segundo ponto interessante diz respeito ao modo como podemos selecionar o subevento pragmaticamente mais relevante. Num evento accomplishment, por exemplo, podemos tornar relevante o subevento do estado inicial, o subevento processo ou o subevento resultado. No significado do nome (de evento) 'fritura', por exemplo, podemos indicar o feitio ou o resultado - o ovo na frigideira ou o ovo pronto para comer. A nossa pergunta deriva facilmente: As crianças selecionam o subevento relevante e relacionam com aspecto gramatical e o tempo?

${ }^{6}$ A more principled semantics is possible on the assumption that the temporal categories of tense, aspect, aspectual adverbials, and of propositions themselves refer to a mental representation of events that is structured on other than purely temporal principles, and to which the notion of a nucleus, or contingently related sequence of preparatory process, goal event, and consequent state, is central." 
Mais do que perguntas para a análise dos nossos dados, temos aqui uma consequência teórica séria, e portanto reveladora: associar as situações do mundo (resgatando o pressuposto ontológico de Vendler) apenas à configuração temporal ou a um sistema de traços ou a uma sequência de operações parece redutor diante da possibilidade de tratá-las como organizações cognitivas dos eventos - entre esquema temporal, participantes, relação hierárquica -, num processo derivacional que a sintaxe mantém. Ou seja, 'estrutura de evento' parece ser um conjunto informacional mais robusto que 'aspecto lexical', ou classe accional ou aktionsart.

Nesse sentido, num texto sugestivamente embrionário, Swart (1998) desenvolve uma análise da mudança de leitura aspectual para aplicá-la a dados do inglês e do francês. Há vários níveis da leitura aspectual. Primeiramente, há a leitura aspectual de dentro da estrutura argumental, o que a autora chamou de descrição de eventualidade. Há também a leitura aspectual que vem de operadores aspectuais, que são o progressivo, o perfeito e os advérbios durativos em in e for, que modificam o valor aspectual da descrição de eventualidade. Mas há também a leitura do tempo (passado, presente, futuro). Swart estende a estrutura geral sintática ([Tense[Aspect[eventuality description]]]) e justifica o escopo do operador temporal maior que o aspectual, pois provou-se que alguns tempos têm restrições aspectuais, como o passé simple e o imparfait do francês.

Embora tratando Aspect e Tense como operadores de coerção de tipo aspectual, dado que o modelo de interpretação semântica é o mesmo, o que nos interessa aqui é a hierarquia proposta. No entanto, para justificar a dissociação entre aspecto gramatical e descrição de evento, em consonância aos nossos dados, optamos por separar a natureza semântica desses passos derivacionais. Nesse sentido, a descrição do evento é a parte mais baixa da derivação, contendo as informações da configuração do evento em suas subestruturas. Essa configuração vem de operações cognitivas que organizam primitivos conceituais codificados no léxico - já em estrutura sintática (JACKENDOFF, 2010). Por sua vez, as operações aspectuais do PERF e IMPERF bem como a leitura temporal do PAST vêm acima, no lugar da operações que 'modelam' as situações.

No modelo nanossintático(STARKE, 2009), essa hierarquia se estrutura em 'zonas' semântico-sintáticas (RAMCHAND \& SVENONIOUS, 2014): a zona do evento (em sua subestrutura), a zona da situação (ou das operações tempo-aspecto-modais) e a zona das proposições (intenções discursivo-pragmáticas):

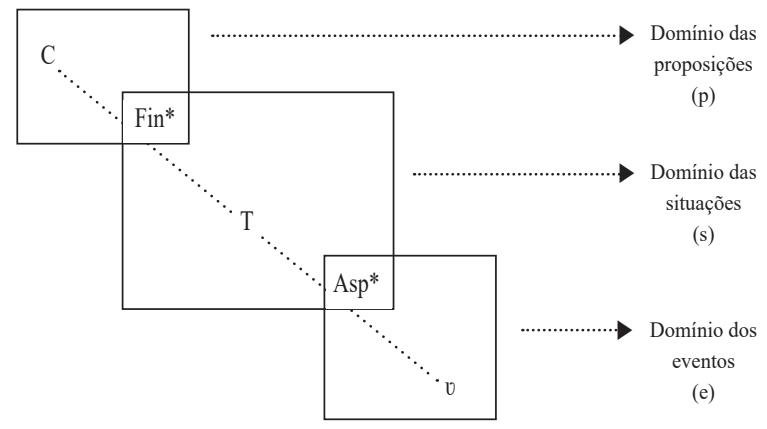

Figura 2: estrutura geral sintática de Ramchand \& Svenonious, 2014. 
No domínio dos eventos, sob a projeção - quase mnemônica ' $v$ ' - a estrutura segue a proposta de Ramchand (2008), de uma sintaxe de "primeira fase", segundo a qual o item lexical passa a ser o resultado de um pedaço de estrutura codificada no léxico. Ou seja, há informação lexical que constrói estrutura argumental, mas ela não está congelada no item lexical. Nesse sentido, a autora relativiza ao mesmo tempo a postura lexical-temática conservadora de Hale \& Keiser (2002), de um lado, e o tratamento construcionista sintático de Borer (2005) e Marantz (2001) (apud RAMCHAND, 2008), de outro.

Em sua concepção sobre a constituição e o comportamento do léxico, a autora determina os primitivos que operam dentro de um sistema de combinação que capture as generalizações fundamentais a respeito de noções como papéis temáticos, estrutura de eventos (aktionsart) e seleção lexical. Assim, a sintaxe de primeira fase, dentro do modelo da Nanossintaxe, propõe uma estrutura eventiva sintaticamente representada, em que subeventos possuem projeções com determinados primitivos.

Categorias primitivas como INITIATOR, PROCESS, UNDERGOER, RESULT, PATH, PLACE - relacionadas aos conhecidos rótulos de agente, processo, afetado, resultado, trajetória, locativo, respectivamente - combinam-se em itens lexicais através de uma estrutura hierarquizada, que acompanha princípios cartográficos e minimalistas (STARKE, 2009). Logo, na representação sintática dessa combinatória, cada um desses primitivos ganha sua projeção em estrutura arbórea:

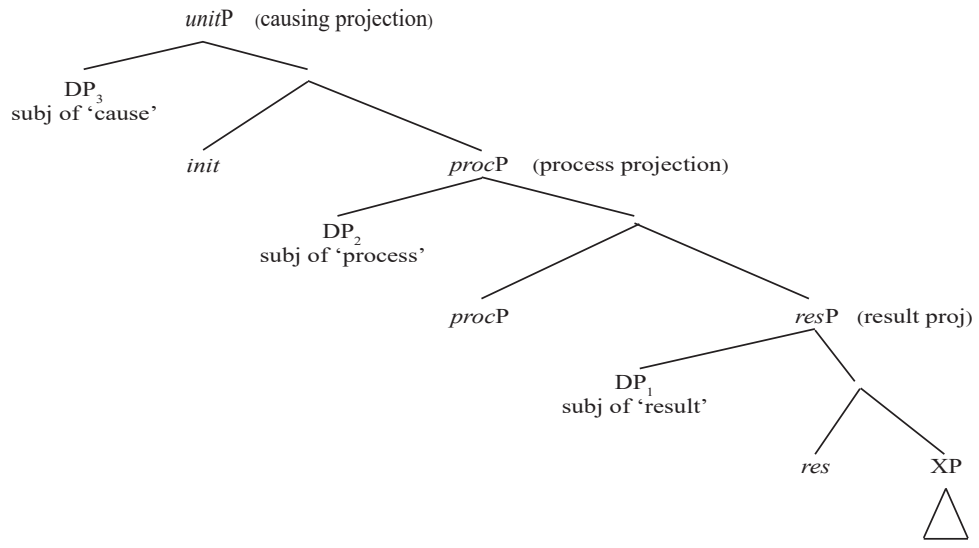

Figura 3: sintaxe de primeira fase, em estrutura de primitivos semânticos, segundo Ramchand 2008, p. 39.

Nessa árvore, inic, proc e res são os núcleos das três projeções correspondentes aos três subeventos. DP3, DP2 e DP1 correspondem aos especificadores INICIATOR, UNDERGOER e RESULT, respectivamente.

INICIATOR são entidades causativas que possuem a propriedade denotada pelo subevento de iniciação, que permite o surgimento do subevento de processo: A pedra quebrou o vidro; Karena dirigiu o carro. 
UNDERGOER são entidades que sofrem alterações de posição/estado. São homomorficamente relacionados com PATHS, ou seja, a escala/medida do movimento/mudança que o UNDERGOER sofre é mensurada à medida que $o$ PATH é "percorrido": Karena dirigiu o carro; $A$ bola rolou; Karena percorreu $a$ trilha; Michael correu até a loja.

RESULTS são entidades que possuem a propriedade de resultado: Michael lavou o cachorro até ficar cheiroso. O complemento de res $\mathrm{P}$ pode ganhar configuração de PathP ou PlaceP.

Também são possíveis papéis compostos, como UNDERGOER-INICIATOR e RESULT-UNDERGOER. Em ambos os casos, um mesmo argumento possui dois papéis: Karina correu até a árvore (UNDERGOER-INICIATOR); Karina dançou. (UNDERGOER-INICIATOR); Miguel empurrou o carro até a loja. (RESULTUNDERGOER); Katarina quebrou o palito. (RESULT-UNDERGOER).

Com esses elementos postos, é possível dizer que um evento conecta itens lexicais em uma estrutura baseada em determinados primitivos. Nesse sentido, Ramchand (2008) defende, na estrutura flexível e inata, que pedaços de estrutura podem ser codificados ou lexicalizados em itens de vocabulário distintos, gerando 'classes naturais de verbos' (p. 108). Mais importante ainda, é possível dizer que o aspecto lexical é uma das informações da estrutura de primeira fase. Seguiremos na análise a notação dos verbos obedecendo às classes naturais dos verbos. Por exemplo, o verbo 'comer', tradicionalmente accomplishment, seria representado por (INIT, PROC, RESULT).

Para o que nos interessa - a relação v / ASP / T nos dados de aquisição do $\mathrm{PB}$-, tomaremos como pressupostos a hierarquia da nanossintaxe entre evento/ situação / proposição, bem como a estrutura de subevento proposta por Ramchand na sintaxe de primeira fase. Na linha da conceptualização de eventos antecedendo operações, o modelo nanossintático parece planejar na sintaxe - esboçada em Swart (1998) - a topografia de evento sugestionada em Moens \& Steedman (1988).

Nesse sentido, o estado pouco homogêneo dos tratamentos teóricos das hipóteses de aquisição de aspecto lexical, aspecto gramatical e tempo (LAFH e GAFH), apresentado por Delidaki (2006), pode agora ganhar outra saída: ao questionarmos a limitação da noção de aspecto lexical, ganhamos a noção de estrutura de evento em representação derivacional nas 'zonas' da derivação. $\mathrm{Na}$ seção seguinte, apresentaremos dados experimentais e longitudinais de crianças do PB que endossam essa inversão no tratamento teórico do evento.

\section{DADOS DAS CRIANÇAS DO PB}

Nesta seção, apresentamos dois experimentos e um levantamento longitudinal, realizados no âmbito dos projetos de pesquisa "Construção de banco de dados para estudos de aquisição de tempo e aspecto no PB" (2008-2012) e "Primitivos semânticos, história e aquisição de estrutura argumental no PB" (2012-2016), na UFPR. Temos a intenção de discutir os resultados que apontam para a distinção entre descrição de evento e aspecto gramatical/tempo, bem como para a hipótese da aquisição esboçada na hierarquia evento $>$ aspecto $>$ tempo, no PB. 
Os experimentos envolveram 32 crianças de uma pré-escola em Curitiba, na faixa etária de 3 a 6 anos, bem como um grupo de 5 adultos, como grupo controle. Com base nos pressupostos inatistas e nas orientações metodológicas em Crain \& Thornton (1998), assumimos inicialmente que as crianças operam um dispositivo de aquisição de linguagem (DAL) no processo de modularidade em direção à gramática do adulto.

Os experimentos consistiram de eventos com estrutura complexa: 'comer macarrão' e 'pintar as unhas', como eventos accomplishments (INIT, PROC, RESULT), e 'fazer o gol' e 'tropeçar', como eventos achievements (INIT, RESULT). Diferentemente de eventos homogêneos, como estados e atividades, essas estruturas nos viabilizam o objetivo de testar a compreensão da configuração interna de subeventos em detrimento ao aspecto gramatical e ao tempo. O primeiro experimento realizou a tarefa de julgamento de aceitabilidade (judgement task) de sentenças no perfectivo/passado para eventos não iniciados; o segundo experimento, a tarefa de indicação de figura de subeventos (act-out task) igualmente em sentenças no perfectivo/passado. Cada criança, isoladamente, era levada a observar as imagens retiradas de revistas da Turma da Mônica e a interagir no experimento com fantoches de cachorros manipulados pelas entrevistadoras.

Quanto aos dados longitudinais, foram selecionados os dados transcritos da faixa etária de 1;7 a 2;4 para o levantamento dos dados de produção de estruturas verbais - estados, atividade, accomplishment, achievement -, agora com relação ao aspecto gramatical e ao tempo verbal: perfectivo/passado e imperfectivo/presente.

\subsection{Teste de julgamento de aceitabilidade em eventos 'comer' e 'fazer o gol'.}

O experimento de compreensão envolveu 11 crianças de 3 a 4 anos, 11 de 4 a 5 anos, e 10 de 5 a 6 anos em uma pré-escola de Curitiba, e mais 5 adultos. Antes do início do experimento, duas pesquisadoras conversavam informalmente com as crianças sobre a Turma da Mônica. Em seguida, apresentavam os fantoches, dois cachorrinhos, e seus respectivos nomes. A sequência de duas imagens - uma de comer o macarrão (fig. 4) e outra de fazer o gol (fig. 5) - foram mostradas em conversa intermediada por um fantoche que dizia a frase "A Magali comeu o macarrão", e outro fantoche perguntava à criança "Sim ou não?". ' As imagens das situações foram propositadamente escolhidas pelo fato de que elas não tinham acontecido ainda:

\footnotetext{
${ }^{7}$ Para evitar o processo do 'yes-bias', no qual as crianças tendem a responder ao julgamento só com o 'sim', para acertar o teste, optamos por elaborar a questão com "Sim ou não?" ou "O que você acha? Sim ou não?", e não "certo ou errado?”. Em ambiente escolar, a avaliação parece perseguir o discurso infantil.
} 


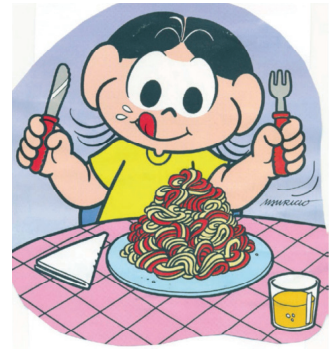

Figura 4: comer o macarrão (INIT, PROC, RESULT)

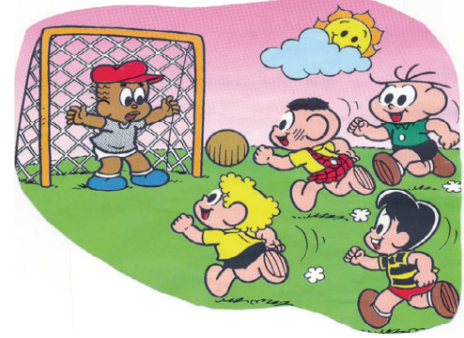

Figura 5: fazer o gol (INIT, RESULT)

Os resultados seguiram um comportamento assimétrico das crianças em relação aos adultos (gráfico 1). No evento de 'comer o macarrão', todas as crianças responderam sim à provocação do fantoche, enquanto os adultos responderam negativamente, ainda com comentários "Claro que não! O macarrão ainda ta todo lá!"

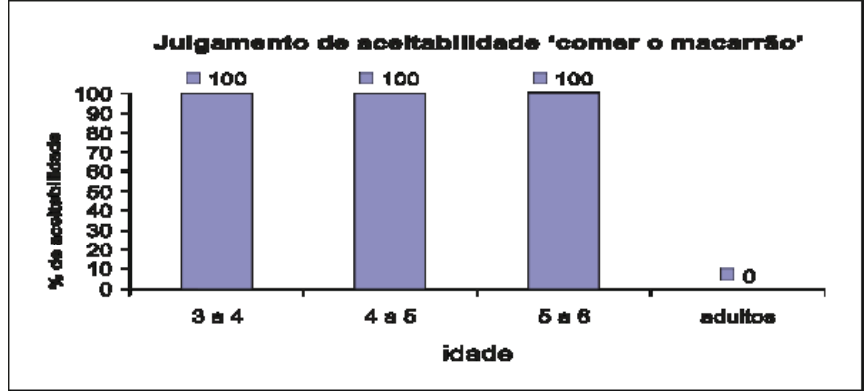

Gráfico 1: Julgamento de aceitabilidade de 'comer o macarrão'.

Na cena de 'fazer o gol', o fantoche 1 dizia a frase "O Cascão fez o gol". À pergunta "sim ou não?" do fantoche 2 , pode-se dizer que as crianças mais velhas, de 5 a 6 anos já esboçaram direção à gramática do adulto: ${ }^{8}$

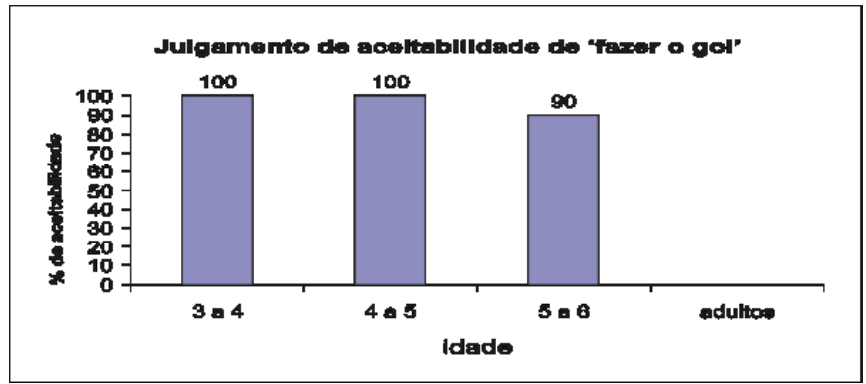

Gráfico 2: Julgamento de aceitabilidade de 'fazer o gol'.

${ }^{8}$ A ocorrência aparentemente aleatória de $10 \%$ de crianças de 5 a 6 anos que não aceitaram a sentença pode indicar a necessidade de realização do teste orientado estatisticamente. Isso consta em nossos projetos futuros. 
Precisamos pontuar que o experimento checou compreensão, e não produção. O levantamento exposto abaixo nos dados longitudinais vai checar produção de outras crianças na variação perfectivo e imperfectivo. No entanto, a assimetria já nos revela uma tendência de as crianças julgarem a cena do evento em detrimento da leitura aspectual e temporal. No modelo hierárquico de Ramchand \& Svenonious (2014) (figura 2), observamos que as crianças operam na zona do evento, enquanto os adultos já acionam operações acima, na zona das situações.

Mas os eventos testados têm estrutura complexa, seguindo a representação topológica de Moens \& Steedman (1988) (figura 1). Para testar a compreensão da subestrutura de evento, desenvolvemos o experimento 2.

\subsection{Teste de compreensão de seleção de figura em eventos 'pintar as unhas' e 'tropeçar'.}

O mesmo grupo de crianças (11 de 3 a 4 anos, 11 de 4 a 5 anos, e 10 de 5 a 6 anos, igualmente ambientadas e reapresentadas aos fantoches) e adultos foram testados diante de duas sequências de imagens. A primeira mostrou três cenas do evento 'pintar as unhas': a primeira com as unhas não pintadas, a segunda com um pincel pintando sendo manipulado para pintar as unhas, e a terceira com as unhas todas pintadas (fig. 6). O fantoche 1 disse a frase "A Mônica pintou as unhas"; e o fantoche 2 fazia o comando: "Mostre pra mim com o dedinho o que o cachorrinho disse."

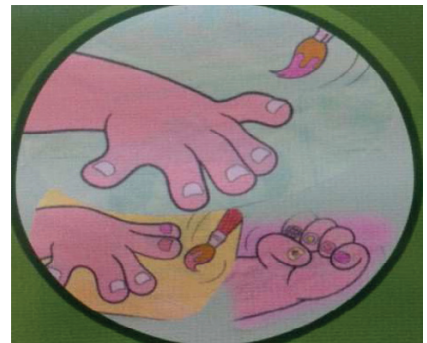

Figura 6: pintar as unhas (INIT, PROC, RESULT)

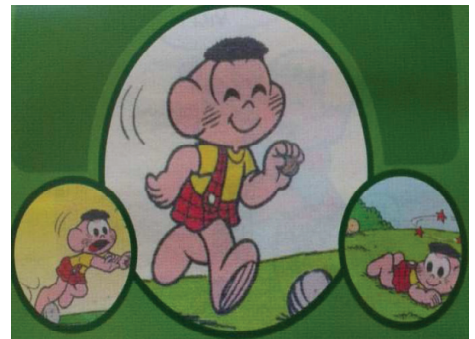

Figura 7: tropeçar (INIT, RESULT)

Os resultados mostraram novamente tendências diferentes entre crianças e adultos. Entre 3 e 5 anos, verificou-se uma oscilação de indicação de subeventos. O subevento de resultado, indicado por $100 \%$ dos adultos, teve indicação das crianças de $36 \%, 63 \%$ e $50 \%$, respectivamente: 


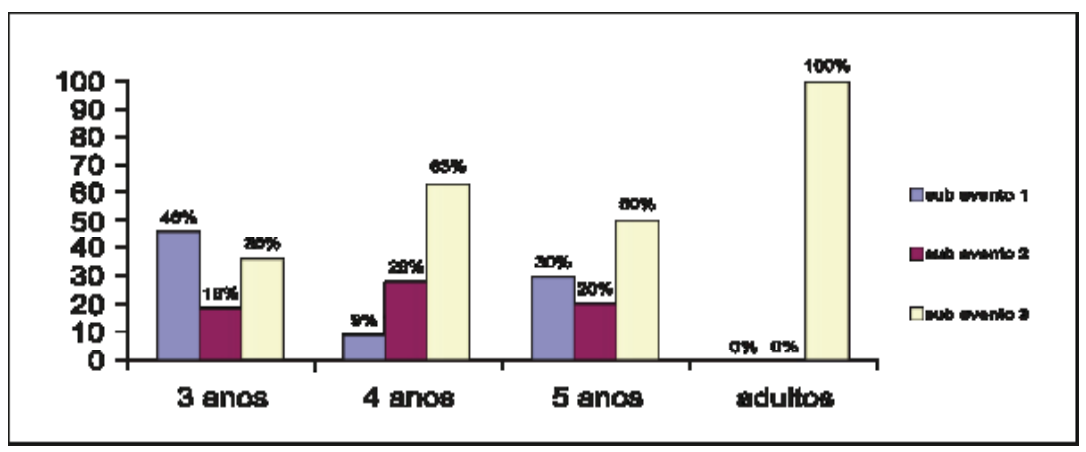

Gráfico 3: Indicação de subevento relevante de 'pintar as unhas'.

Na segunda sequência de cenas, o evento pontual de 'tropeçar' mostrava as seguintes cenas: na primeira, o Cascão caminhando e uma pedra à frente; na segunda, o movimento iminente de cair; e na terceira, o Cascão já caído no chão (fig. 7). ${ }^{9} \mathrm{~A}$ mesma tarefa era apresentada à criança, quando o Fantoche 2 pedia para ela mostrar com o dedinho o que o outro disse ("O Cascão tropeçou"). Os resultados mostraram tendência de as crianças selecionaram o subevento 2 (36\% para as de 3 anos, $55 \%$ para as de 4 anos e $60 \%$ para as de 5 anos), e um comportamento agora não tão homogêneo dos adultos:

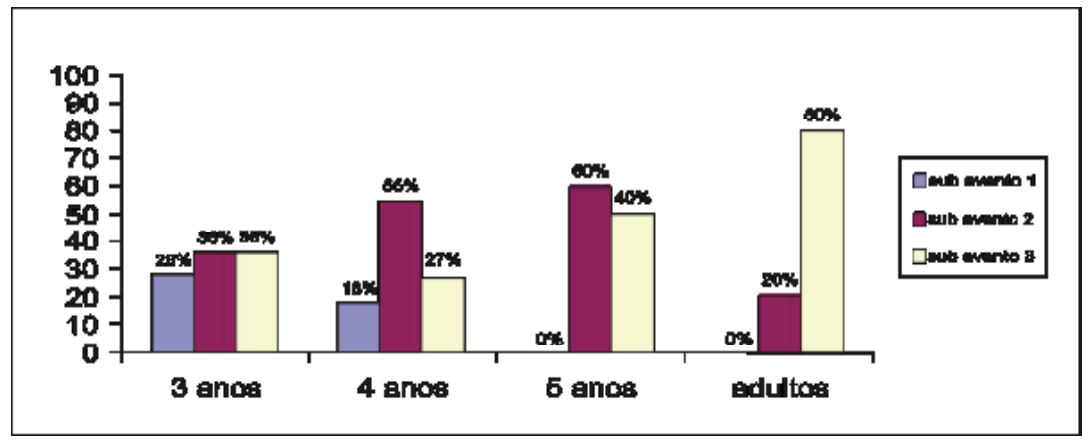

Gráfico 4: Indicação de subevento relevante de 'tropeçar'.

O comportamento assimétrico das crianças revela a oscilação na interpretação do evento. Mas os adultos tenderam à operação de aspecto gramatical e tempo. No entanto, os dois experimentos acima revelam o comportamento de compreensão das crianças. Com os dados longitudinais de outras crianças, pudemos realizar o levantamento das opções evento, aspecto, tempo no relato que segue abaixo.

${ }^{9}$ Por razões de espaço, reproduzimos aqui a montagem feita no banner exibido na seção de pôsteres do Workshop on Formal Linguistics, realizado na UFPR, em 2008. É importante frisar que para as crianças - a sequência de subeventos foi mostrada na ordem correta descrita acima.

${ }^{10} \mathrm{~A}$ escolha dessa faixa etária se justifica pelo fato de ser o período em que, segundo autores como Wagner (2006), a telicidade seria o bootstraping para a aquisição da categoria de tempo. 


\subsection{Dados longitudinais}

Os resultados dos dados longitudinais, coletados de três crianças entre 1; 7 e $2 ; 4^{10}$ consistem em registros de fala mensal, de 10 a 15 minutos por gravação. No levantamento dos verbos produzidos pelas crianças, excetuando-se o fenômeno de ecolalia, em que a criança repete insistentemente algum verbo falado pelo adulto, constataram-se as tendências de se usar verbo no estativo (INIT) em flexão do presente, bem como verbos pontuais achievements (INIT, RESULT) em situação de evento dêitico (que aconteceu na situação imediata) na morfologia do passado:

\begin{tabular}{|c|c|c|}
\hline \multirow{2}{*}{$\begin{array}{c}\text { Análise de produção longitudinal } \\
(1 ; 7 \text { a } 2 ; 4)\end{array}$} & \multicolumn{2}{|c|}{ flexão } \\
\cline { 2 - 3 } & perfectivo & imperfectivo \\
\hline atividade & 0 & 1 \\
\hline estado & 0 & 22 \\
\hline accomplishment & 0 & 0 \\
\hline achievement & 20 & 1 \\
\hline
\end{tabular}

Tabela 1: Dados longitudinais nas leituras aspectuais (lexicais e gramaticais)

Os dados sugerem, de imediato, que a Hipótese do aspecto em primeiro lugar (LAFH), em que aspecto lexical e gramatical convergem em dados iniciais (perfectivo com télico, e imperfectivo com atélico), se confirma parcialmente. De fato, em verbos pontuais de achievement a primeira convergência acontece. No entanto, chama a atenção que, na convergência imperfectivo com atélico, os dados são de verbos estativos no presente: "Táaa... papá” (Tá, papai), Bi, 1;7; ou "Deixa eu vê... ta sonando" (Tá sonhando), A, 2;4. Só houve produção de uma estrutura atividade: "Tá nadando" (B, 2;1).

Nesse sentido, as sentenças em presente estativo mostram a atitude de as crianças 'apresentarem' situações, em estruturas impessoais (VIOTTI, 1999), ao passo que as do passado perfectivo pontuais mostram a criança predicando sobre eventos imediatos (LOPES, 2003). Há diferença discursiva, portanto: apresentar e predicar. Com isso, novamente invertendo o foco na (a)telicidade e (im) perfectividade, sugerimos aqui que conceitos semânticos e estruturas sintáticas podem ter mais critérios de análise.

Em análise mais detalhada, se a convergência fosse télico/perfectivo e atélico/ imperfectivo, a assimetria da tabela acima envolveria as duas linhas de cima em detrimento das duas linhas de baixo. Mas a diferença significativa ocorreu entre estado/imperfectivo/presente e achievement/perfectivo/passado. As orientações de predicação e de apresentação, respectivamente, e não necessária e exclusivamente a telicidade, estão orientando as produções dessa faixa etária inicial. 


\section{CONSIDERAÇÕES FINAIS}

A pesquisa em aquisição de língua materna é sempre desafiadora, assim como se revelam os crescentes estudos de linha experimental nos quais mergulhou a linguística brasileira nos últimos anos. Tanto melhor: de racionalismo e empiricismo, o olhar científico intui que é necessário relacionar os dois planos epistemológicos.

Mas a imbricada aquisição de aspecto (lexical e gramatical) em sua relação com o tempo mostra dados bastante heterogêneos, acompanhados de teorias igualmente pouco conciliatórias. Nossa intenção aqui passa longe de apresentar respostas categóricas, mas sim questionar o estado de propostas para a questão - haja vista a discussão dos trabalhos na seção 2, especialmente a assimetria mostrada nos resultados dos testes de Delidaki (2006).

Nossos testes (seção 4) também permitem questionar as hipóteses dos trabalhos anteriores, uma vez que, a partir deles, saímos da consideração restrita a categorias, como a telicidade, e partimos para a estrutura de eventos. O primeiro teste, de compreensão, sugere que, ao contrário dos adultos que fazem leitura temporal, as crianças leem o evento. No julgamento de aceitabilidade, elas não fizeram a relação entre o passado da pergunta (com os verbos comer e fazer) com a não conclusão dos eventos representados nas imagens observadas - incoerência percebida pelos adultos. Já o segundo teste traz uma evidência de que as crianças oscilam na compreensão dos subeventos. Logo, se a hipótese de que as crianças usam o passado para marcar telicidade estivesse absolutamente correta, a escolha da última figura - indicação do evento concluso - predominaria em todas as faixas etárias.

Nesse sentido, os resultados dos nossos testes de compreensão se aproximam dos realizados por Delidaki (2006), já que levam à possível conclusão de que a compreensão de tempo pela criança não depende diretamente da telicidade.

Os dados longitudinais, por sua vez, não permitem que se infira o padrão da LAFH, como feito por Antinucci e Muller (1976, apud Delidaki 2006). Neles, apenas observamos uma predominância de verbos achievements no passado perfectivo e verbos estativos no presente imperfectivo - do que não se pode generalizar o paralelo entre telicidade e perfectividade, já que não há registro suficiente de verbos de atividade (também atélicos). Surge, então, a necessidade de realização de testes de produção.

Voltando à estrutura de Ramchand \& Svenonious (2014) (figura 2), podemos dizer que, na hierarquia que ela apresenta, as crianças primeiro leem o nível do evento e mais tarde operam no tempo. Essa precedência do evento pode sinalizar um caminho sobre como a criança vai "desmembrando" a categoria sincrética inicial proposta por Bertinetto (2009). Dessa forma, vislumbramos na estrutura sintática de subeventos uma alternativa para regular a lupa sobre os dados em critérios mais detalhados semanticamente e estruturados sintaticamente. 


\section{REFERÊNCIAS}

BACH, E. The algebra of events. Linguistics and Philosophy, n. 9, 1986, pp. 5-16.

BERTINETTO, P. M. Intrinsic and extrinsic temporal reference. On restricting the notion of 'reference time', In: Journal of Italian Linguistics. 1982, pp. 71-108.

BERTINETTO, P. M. On a Frequent Misunderstanding in the Temporal-Aspectual Domain: The 'Perfective-Telic Confusion'. In: CECHETTO, C. et al. (org.). Semantic Interfaces: reference, anaphora and aspect. Standford, Califórnia: CSLI Publications, 2001. pp. 117-210.

BERTINETTO, P. M. Tense-Aspect acquisition meets typology. Quaderni del Laboratório di Linguistica, 2009.

BERTINETTO, Pier Marco; NOCCETTI, Sabrina. Prolegomena to ATAM acquisition - theoretical premises and corpus labeling. (mimeo)

BERTINETTO, P. M.; LENCI, A. NOCCETTI, S. AGONIGI, M. The indispensable complexity (When harder is easier). Lexical and grammar expansion in three Italian L1 learners. Quaderni del Laboratório di Linguistica, 2007-8.

BRONCKART, J-P, SINCLAIR, H. Time, tense and aspect. In: Cognition, 1973.

CRAIN, S.; THORTON, R. Investigations in universal grammar - a guide to experiments on the acquisition of syntax and semantics.MIT Press, 1998.

DAVIDSON, D. Essays on actions and events. Oxford: Carendon Press, 1967.

DELIDAKI, S. The acquistion of tense and aspect in child greek. Tese (Doctor of Philosophy). University of Reading, 2006.

DOWTY, D. Word meaning and montague grammar. Dordrecht: Reidel, 1979.

HALE, K; KEYSER, S. J. Prolegomenon to a theory of argument structure. The MIT Press, 2002.

JACKENDOFF, R. Your theory of language evolution depends on your theory of language. In: Larson, $\mathrm{R}$ et al. (Eds.). The evolution of language: biolinguistics perspectives. Cambridge, 2010, pp. 63-72.

LANGACKER, R. W. Proceedings of the Nineteenth Annual Meeting of the Berkeley Linguistics Society: General Session and Parasession on Semantic Typology and Semantic Universals, 1993, pp. 447-463.

LOPES, R. Katar, kata, katou: a aquisição do objeto nulo e sua relação com aspecto. In: Castilho, A.; Morais, M. A. T.; Cyrino, S.M.L. (Orgs). Descrição, história e aquisição do português brasileiro. São Paulo: Fapesp, Campinas: Pontes Editores, 2007, pp. 673-686.

MOENS, M; STEEDMANN, M. Temporal ontology and temporal reference. In: Computational Linguistics, vol. 14, no. 2, 1988, pp. 15-28.

NEGRÃO, E. V., \& VIOTTI, E. (2011). A ergativização do português brasileiro: Uma conversa continuada com Carlos Franchi. In D. da Hora \& E. V. Negrão (Eds.), Estudos da linguagem. Casamento entre temas e perspectivas (pp. 37-61). João Pessoa, PA: Ideia Editora Universitária.

PARSONS, T. Events in semantics of English: a study in subatomic semantics. Cambridge, Massachusetts/ London, England: The MIT Press, 1990. 
PUSTEJOVSKY, J. The syntax of event structure. In: Cognition, 41, 1991, p. 47-81.

RAMCHAND, G. C. Verb meaning and the lexicon. Cambridge, 2008.

RAMCHAND, G.; SVENONIUS, P. Deriving the functional hierarchy. In: Language sciences, v. 46, 2014.

REICHENBACH, H. Elements of symbolic logic. New York: Macmillan, 1947.

ROTHSTEIN, S. Structuring Events: a study in the semantics of lexical aspect. Blackwell, 2004.

SMITH, C. S. The syntax and interpretation of temporal expression in English. In: Linguistics and Philosophy, 2, 1978, pp. 43-99.

SMITH, C. S. The parameter of aspect. Dordrecht: Kluwer, 1997.

SWART, H. de. Aspect shift and coercion. Natural language and linguistic theory, v. 16, n.. 2, 1998, pp. 347-385.

STARKE, M. Nanosyntax: A short primer to a new approach to language. Nordlyd, v. 36, n. 1: Special issue on Nanosyntax, 2009.

VENDLER, Z. Linguistics in philosophy. Ithaca (NY): Cornell University Press, 1967.

VIOTTI, E. de C. A sintaxe das sentenças existenciais do português do Brasil. São Paulo, 1999. 292 f. Tese (Doutorado em Lingüística) - FFLCH, USP.

WAGNER, L. Aspectual influences on early tense comprehension. J. Child Lang. 28 2001, pp. 661-681.

WAGNER, L. Aspectual Bootstrapping in Language Acquisition: Telicity and Transitivity. LANGUAGE LEARNING AND DEVELOPMENT, 2(1), 2006, pp. 51-76. 